\title{
ANDES

\section{Instrumentos breves: Un método para validar el contenido de los ítems}

\section{Short instruments: A method for validating item content}

\author{
José Ventura-León ${ }^{\mathrm{a}}$
}

aUniversidad Privada del Norte. Lima, Perú

Los instrumentos breves son frecuentemente utilizados en el contexto de la investigación infantil. Un reciente estudio en la Revista Chilena de Pediatría demuestra su vigencia ${ }^{1}$. Esta tendencia esta motivada por la necesidad de contar con instrumentos que permitan una rápida exploración del niño evitando la fatiga de responder muchas preguntas. De ese modo, los instrumentos breves pueden ser definidos como aquellos instrumentos con diez o menos ítems ${ }^{2}$ y con frecuencia diseñados para la detección o tamizaje de alguna variable de interés ${ }^{3}$. Su énfasis se subyace en contar con pocos ítems y al mismo tiempo mantener la amplitud conceptual de lo que mide.

En ese contexto, la principal crítica de los instrumentos breves es la insuficiencia conceptual o baja representación de la variable a medir ${ }^{4}$. Es decir, del universo de comportamientos que puede presentar una variable, las seleccionadas y que son parte del test son suficientes para capturar la esencia conceptual de la variable. Un procedimiento típico que puede paliar este cuestionamiento es que los ítems sean revisados por un panel de expertos; quienes a través de un formato establecido pueden examinar la idoneidad de las conductas seleccionadas ${ }^{5}$. Sin embargo, un procedimiento alterno basado en los principios del análisis temático (técnica cualitativa) ${ }^{6}$ y estrategias de revisión sistemática podrían proporcionar una solución elegante al problema de insuficiencia conceptual. Esta pro- puesta tiene la no recurrencia a una gran cantidad de expertos; pues, se sostiene en las estrategias de análisis, deducción y sistematización del investigador o grupo de investigación que realiza el estudio.

Un ejemplo ayudará a su comprensión. Imagine que desea validar los ítems de un test breve que mide la fobia a la oscuridad en un grupo de niños asistentes a una institución pediátrica (Tabla 1). Inicialmente, el investigador debe realizar una búsqueda en base de datos o repositorios especializados. Una vez realizado este procedimiento se organiza la información en cuatro fases: (a) Familiarización, se consigna en forma literal en una tabla la información para ser leída y releída; (b) Segmentación, se identifica los segmentos de información relevantes; (c) Categorización, se organizan los segmentos de información por su similitud; y (d) Correspondencia, se examina si las categorías generadas están inmersas en el contenido de los ítems.

Tal como se observa em la Tabla 1, la fobia a la oscuridad es un suceso que ocurre en la habitación del menor y asociado con ir a dormir. Es decir, se señala que test mide algo muy especifico del constructo y los tres ítems capturan lo esencial. Es más, la Tabla 1 puede convertirse (si se anexa en un trabajo de investigación) en evidencia acerca del contenido de los ítems. Un aspecto resaltante del proceso es que solo uno de los autores expone la categoría Fantasía, que fue incluido en la categorización porque a juicio del observador

Correspondencia:

José Ventura-León

jventuraleon@gmail.com 


\section{Tabla 1. Cuadro comparativo de diferentes definiciones de la fobia a la oscuridad (Ejemplo del método propuesto)}

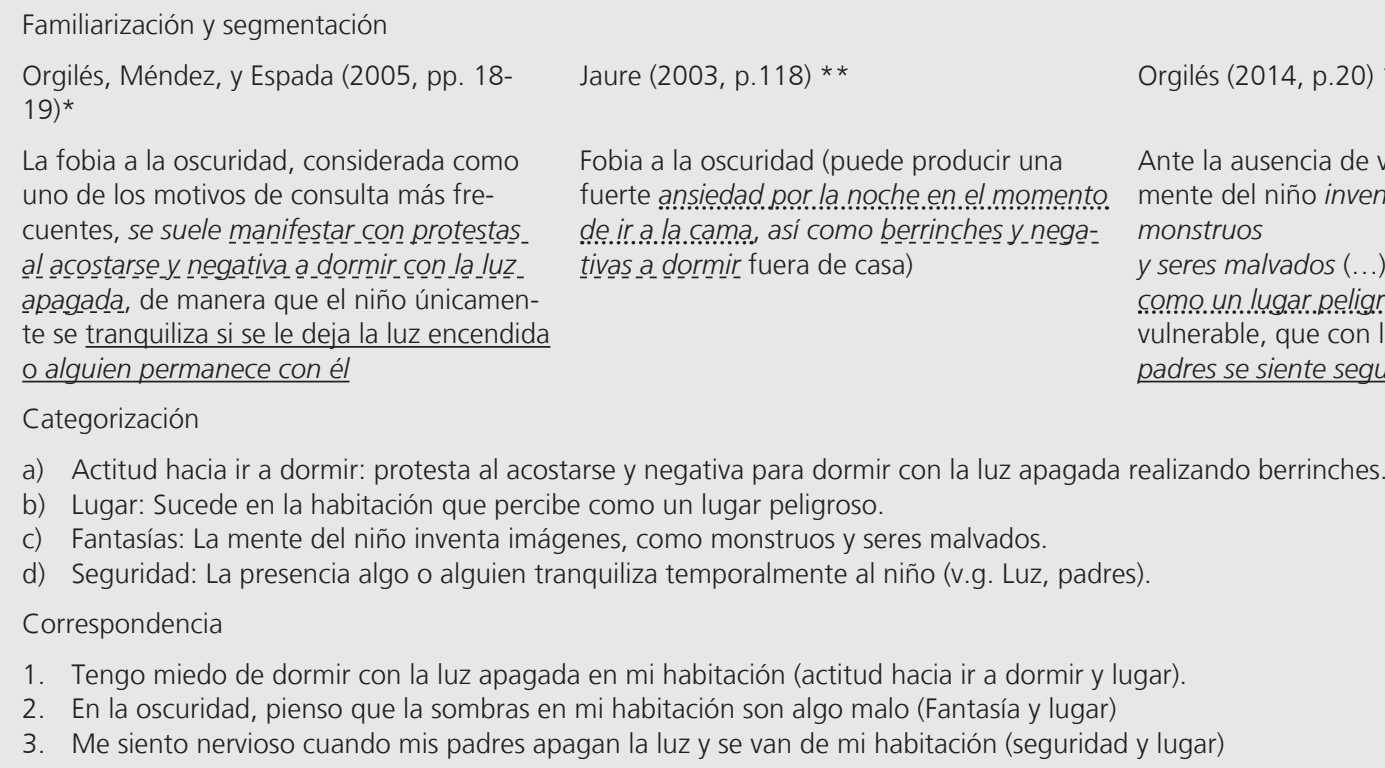

La fobia a la oscuridad, considerada como uno de los motivos de consulta más frecuentes, se suele manifestar con protestas al acostarse y negativa a dormir con la luz. apagada, de manera que el niño únicamente se tranquiliza si se le deja la luz encendida o alguien permanece con él

Categorización

a) Actitud hacia ir a dormir: protesta al acostarse y negativa para dormir con la luz apagada realizando berrinches

b) Lugar: Sucede en la habitación que percibe como un lugar peligroso.

c) Fantasías: La mente del niño inventa imágenes, como monstruos y seres malvados.

d) Seguridad: La presencia algo o alguien tranquiliza temporalmente al niño (v.g. Luz, padres).

Correspondencia

1. Tengo miedo de dormir con la luz apagada en mi habitación (actitud hacia ir a dormir y lugar).

2. En la oscuridad, pienso que la sombras en mi habitación son algo malo (Fantasía y lugar)

3. Me siento nervioso cuando mis padres apagan la luz y se van de mi habitación (seguridad y lugar)

Nota: La cursiva denota el segmento relevante (segmentación). Los diferentes tipos de subrayado indica la similitud de los segmentos de información (Categorización). Fuente: *Orgilés M, Méndez X, Espada J. Tratamiento de la fobia a la oscuridad mediante entrenamiento a padres. Psicothema [Internet]. 2005 [cited 2021 Jul 19];17(1):9-14. Available from: www.psicothema.com. **Jaure CM. Las fobias: todo lo que necesita saber. Buenos Aires, Argentina: Imaginador; 2003. ***Orgilés M. Tratando... fobia a la oscuridad en la infancia y adolescencia. Madrid, España: Pirámide; 2014.

(quien realiza el análisis) es un aspecto importante por considerar. Si hubiera duda de mantener esta categoría la Tabla 1 puede ser proporcionada a otro investigador a modo de triangulación. Asimismo, la tabla 1 puede utilizarse como parte del proceso de construcción de un test para la generación de ítems, cuya riqueza consistirá en la búsqueda y exposición de diferentes autores en la fase de familiarización.
En conclusión, un test breve no es una medida menos válida por su cantidad de ítems, sino por la ausencia de evidencia acerca del contenido de los tales. De ese modo, es necesario proporcionar métodos que permitan evidenciar el proceso de derivación de los ítems y su correspondencia con los postulados teóricos. Esto resulta coherente con uno de los principios fundamentales en ciencia como es la replicabilidad.

\section{Referencias}

1. Sierra-Zúñiga $\mathrm{M}$, Betancourt $\mathrm{CH}$, Mera-Mamián AY, Delgado-Noguera $\mathrm{M}$, Calvache JA. Construction and validation of an instrument to measure knowledge of mothers and caregivers on complementary feeding of infants. Rev Chil Pediatr. 2020;91(5):711-21.

2. Ziegler M, Kemper CJ, Kruyen P. Short Scales-Five Misunderstandings and Ways to Overcome Them. J Individ
Differ [Internet]. 2014 Jan 1;35(4):185-9. Available from: https://econtent.hogrefe. com/doi/10.1027/1614-0001/a000148

3. Villarejo A, Puertas-Martín V. Utilidad de los test breves en el cribado de demencia. Neurología [Internet]. 2011;26(7):425-33. Available from: https://linkinghub.elsevier.com/retrieve/ pii/S0213485310003312

4. American Educational Research Association, American Psychological Association, National Council on
Measurement in Education. Standards for educational and psychological testing. 7th ed. Washington, DC: American Educational Research Association; 2014.

5. Ventura-León J. De regreso a la validez basada en el contenido. Adicciones [Internet]. 2019; Available from: http:// adicciones.es/index.php/adicciones/ article/view/1213

6. Braun V, Clarke V. Using thematic analysis in psychology. Qual Res Psychol. 2006;3(2):77-101. 